\title{
Presence of natural fracture as an indicator of operational difficulty for cave operations
}

\author{
M Munkhchuluun Oyu Tolgoi LLC, Mongolia \\ D Elmo The University of British Columbia, Canada \\ S Nadolski The University of British Columbia, Canada
}

A Moss Sonal Mining Technology, Canada

B Klein The University of British Columbia, Canada

\begin{abstract}
Cave mining methods are becoming the methods of choice due to their potential to extract ore from large low-grade deposits at depth at production rates comparable to open pit mines. However, the high upfront capital related to the degree of development and time lag before production require detailed planning and reliable studies to cope with the associated risks. One important geotechnical issue is managing rock mass fragmentation that affects both project value and safety.

Both the scale of the problem and the lack of direct access to the rock mass at project evaluation and design stages make characterisation and accurate prediction of rock mass fragmentation a very difficult task. In this context, caving geomechanics is still largely an empirically based exercise. The discrete fracture network (DFN) approach uses fracture data collected from mapping of boreholes and rock exposures. The DFN approach was used to generate an in situ fragmentation model for the New Afton B1 Cave. The volumetric fracture intensity value $\left(P_{32}\right)$ is used as an indicator of the rock mass's structural character, and provides a direct link to rock mass fragmentation. Major structures were included in the model and the spatial variability of the fracture intensity was analysed to derive a geostatistical model of rock mass fragmentation. The fragmentation 'block model' was then superimposed onto New Afton's PCBC TM historical draw schedule model in an attempt to report blocks, representing the in situ fragmentation to drawpoint with respect to historical logs of hang-up event frequency, which also can refer back to height of draw (HOD). It was found that the influence of natural fractures diminishes gradually as the HOD increases. This is largely due to comminution in the draw column. The results showed that the model could identify areas of high hang-up events during initial draw prior to the column reaching maturity with respect to fragmentation.
\end{abstract}

Keywords: caving operation, fragmentation, discrete fracture network, hang-up event, height of draw, piecewise linear interpolation, fracture frequency

\section{Introduction}

For low-grade, disseminated massive orebodies at depth, caving methods allow for high efficiency and low production costs. The caving mechanism can be explained by fracturing of the unsupported cave back which progresses as the broken rock is removed from the production level after traveling through the column of caved materials (Figure 1). This process of cave-induced fracturing and the subsequent movement of caved material to the drawpoint results in three distinctive fragmentation phases that can be differentiated, including (i) in situ fragmentation (naturally interlocked blocks), (ii) primary fragmentation (blocks that detach from the cave back as the cave is initiated), and (iii) secondary fragmentation (blocks that are fragmented as the consequence of downward ore flow) (Brown 2003). Depending on the dominance of the respective fragmentation phases, both oversize and fine caved material, will move to drawpoints, bringing operational difficulties such as hang-ups and migration of fine caved material. Due to the scale of the problem and lack of direct access to the rock mass, prediction of the fragmentation is still 
largely an empirically based discipline (Vyazmensky et al. 2010). However, cave-scale rock mass structures can be described in 3D from available fracture data sampled from boreholes (1D) and rock exposures (2D) using the DFN approach which takes account of natural variability from statistical distribution of fracture properties. This paper discusses an approach undertaken at the New Afton Mine to predict the worst period of hang-up event frequency.

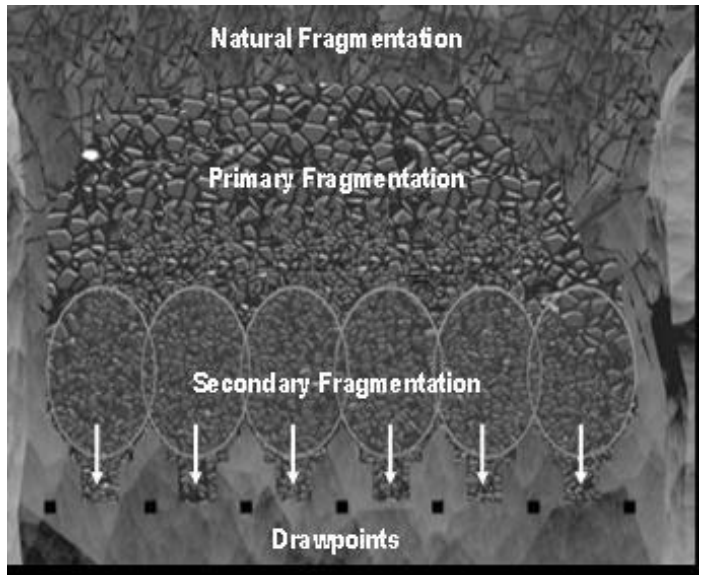

Figure 1 Schematics of natural, primary and secondary fragmentation (modified from Elmo et al. 2014b)

\section{New Afton block cave mine}

The New Afton block cave mine, located in British Columbia, Canada extracts copper and gold from two caves with daily throughputs of $17,500 \mathrm{t}$. The adjacent B1 and B2 Caves have dimensions of approximately $1,500 \mathrm{~m}$ east-west, $800 \mathrm{~m}$ north-south, and $615 \mathrm{~m}$ below ground surface.

The deposit is located within crystalline and polylithic fragmental volcanics and lesser monolithic intrusive breccias and is transected by many faults which are commonly carbonate-healed (Davies 2015). Figure 2 is a plan of the extraction level showing geological and structural features. The B1 Cave is more faulted than the B2 Cave. Also, a less competent unit, picrite, is bound to the footwall side of orebody (south). The principal intrusive monzonite in the south-central part of deposit represents the most competent rock type. The orebody's rock mass rating $\left(\mathrm{RMR}_{76}\right)$ within the mine footprint ranges between $35-55$ with lower values being found in the B1 Cave due to more intense faulting in the east cave due to frequent fault occurrence. Orientation of the main joint set is dipping $76^{\circ}$ in $8^{\circ}$ azimuth direction (Bergen et al. 2015).

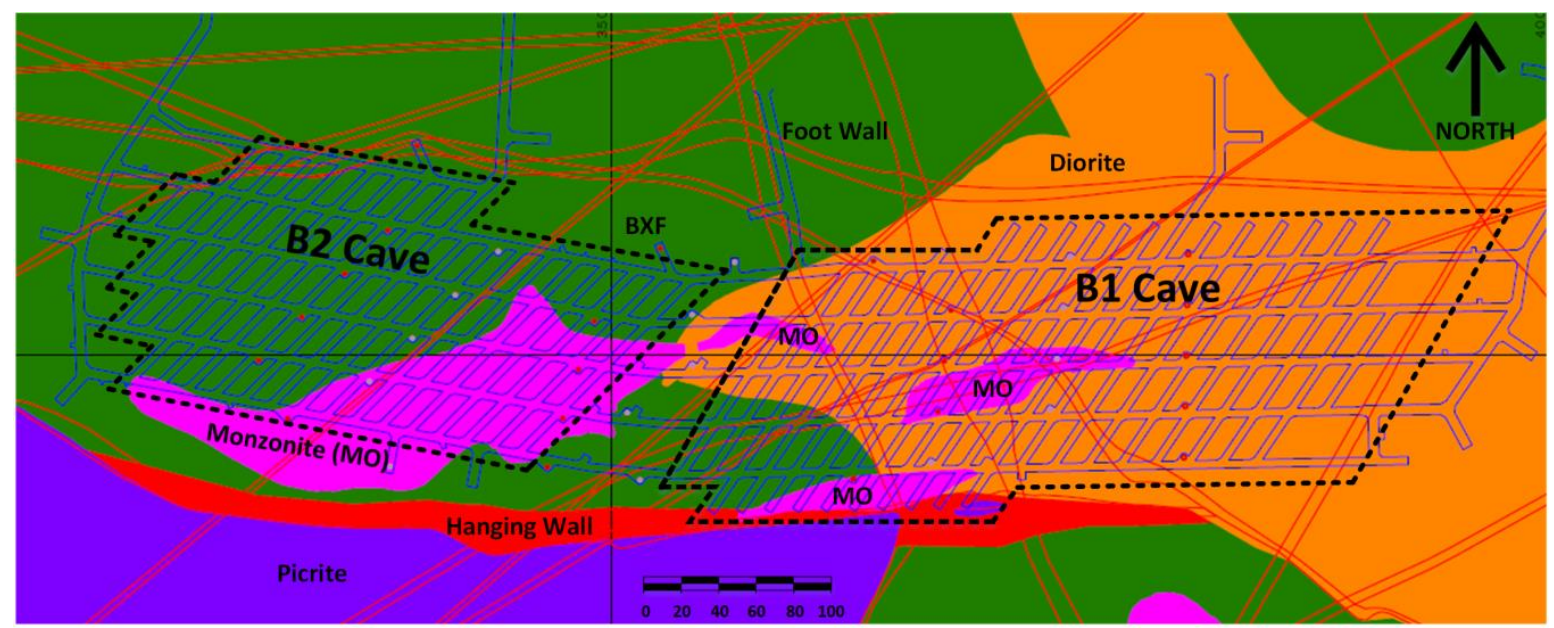

Figure 2 Geological and major structures elements at the extraction level (modified from Nadolski et al. 2017) 


\section{Data limitation and assumption}

The datasets used for generating the DFN model include boreholes and mapping of the apex level (Figure 3). The data collection method is a key component of DFN modelling (Elmo et al. 2015). Only limited oriented borehole and drift mapping data was available, which somehow impacted the generation of the DFN model.

When logging a borehole, zones of missing or broken core were assigned an arbitrary fracture frequency value (e.g. 99 or 55 fractures per metre). When included in the geostatistical analysis of volumetric fracture intensity, the presence of those unrealistic fracture frequency intervals would have skewed the interpolation process. To circumvent a probable overestimation of fracture frequency, intervals corresponding to broken core or missing core were assigned a nominal fracture frequency value (10) that would still yield a rock quality designation (RQD) value of 10 . The presence of well-defined (deterministic) faults or shear zone was later re-assessed in the DFN-based block model in a deterministic manner by manually introducing fault zones.

Veining can have a significant impact on the strength of jointed rock blocks (primary fragmentation), and the degree of secondary fragmentation (Jakubec 2013; Kaiser et al. 2015; Turichshev \& Hadjigeorgiou 2015; Bewick \& Kaiser 2016). Even though vein data was flagged along rock cores, precise information (location and frequency) of veins was not available. Therefore, it was decided to not include vein data in the DFN model.

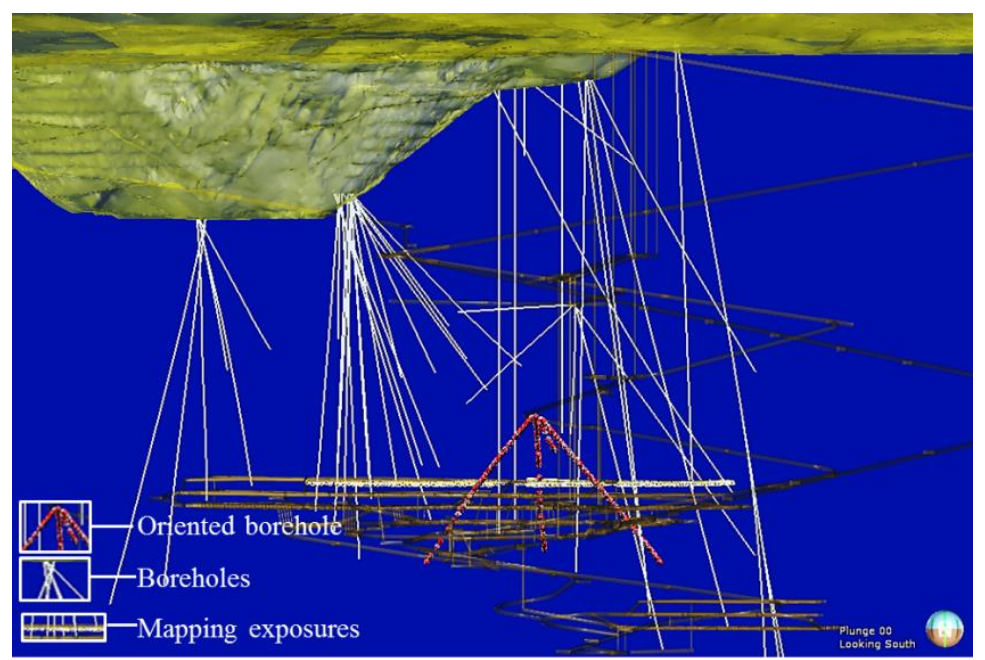

Figure 3 Location of boreholes, mapping exposure and mine infrastructures

\section{$4 \quad$ Discrete fracture network modelling}

Generation of a DFN model typically requires the definition of (i) fracture spatial model, (ii) fracture intensity, (iii) fracture orientation, (iv) fracture size (length), and (v) fracture terminations. The fracture orientation and fracture size distributions are defined as discussed in Elmo et al. (2014a), while fracture terminations are not assumed in the model due to unavailability of the data.

Fracture intensities can be described in a variety of ways depending on scales of fracture in varying dimensions (Dershowitz \& Herda 1992). 1D linear intensity $\left(P_{10}, \mathrm{~m}^{-1}\right.$, defined as the ratio of the total number of fractures intersected's unit length), 2D areal intensity $\left(P_{21}, \mathrm{~m} / \mathrm{m}^{2}\right.$, defined as the ratio of the total fracture length to unit area), and 3D volumetric intensity $\left(P_{32}, \mathrm{~m}^{2} / \mathrm{m}^{3}\right.$, defined as the ratio of the total fracture area to unit volume) are interconnected yet distinct in the way they introduce directional bias. Numbers of fractures are inherently missed due to the orientation of boreholes/scanlines in relation to the orientation of fractures. A 3D representation of discontinuities can be potentially constructed from fracture properties using the DFN approach, and fracture intensities, derived from boreholes/scanlines, can be translated into 3D volumetric intensity known as the ' $\mathrm{P}_{10}$ conditioning method' (Elmo et al. 2008, 2014a, 2014c). 
The $\mathrm{P}_{32}$ can be determined using the following steps:

Step 1: Segmenting similar fracture frequency domains from the cumulative fracture intensity plots using piecewise linear interpolation (Munkhchuluun 2017) as shown in Figure 4.

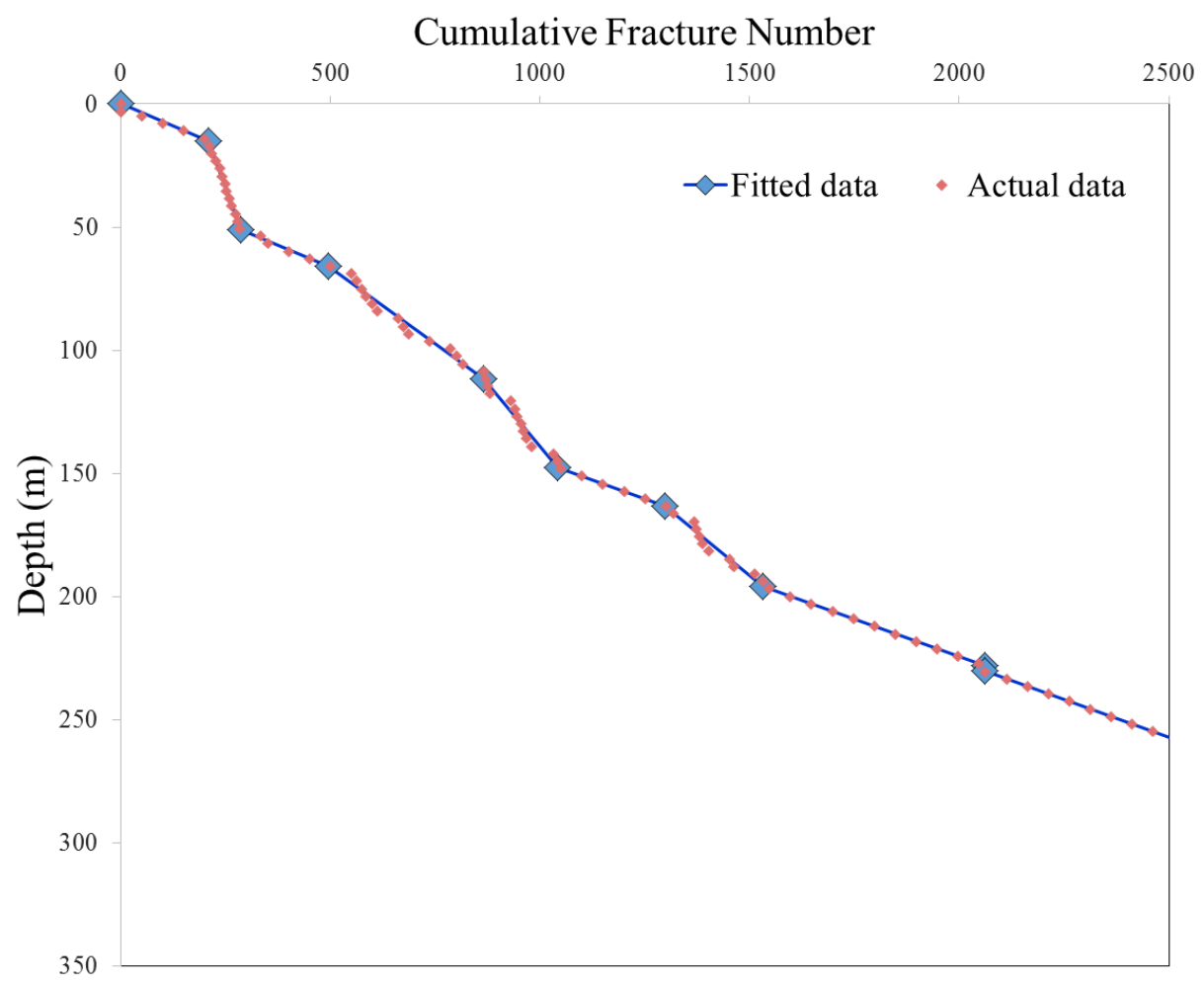

Figure 4 Cumulative fracture intensity plot of borehole UA07-107 (Munkhchuluun et al. 2017)

Step 2: Within the region of $16 \times 16 \times 16 \mathrm{~m}$, a number of DFN models are generated using the fracture orientation, fracture length (Table 1$)$ and varying volumetric fracture intensity $\left(P_{32}\right.$ of $1,3,5$, and 7$)$. Subsequently, simulated boreholes, which were oriented to represent groups of boreholes (Table 2), were inserted into the region to determine the number of fractures intersecting the borehole.

Table 1 DFN input parameters

\begin{tabular}{|c|c|c|}
\hline Data type & Data source & DFN model \\
\hline Spatial analysis & - & Enhanced Baecher \\
\hline \multirow[t]{2}{*}{ Orientation } & 2D mapping on apex level exposures & Bootstrap method \\
\hline & $\begin{array}{l}\text { Four geological oriented borehole from } \\
\text { borehole }\end{array}$ & \\
\hline Intensity & $\begin{array}{l}\text { Borehole-derived } \mathrm{P}_{10} \text { values from } \\
45 \text { boreholes }\end{array}$ & $\begin{array}{l}\text { Volumetric fracture } \\
\text { frequency }\left(P_{32}\right)\end{array}$ \\
\hline Length & 2D mapping on apex level exposures & $\begin{array}{l}\text { Log-normal mean } 2 \mathrm{~m} \text {, } \\
\text { standard deviation } 2 \mathrm{~m}\end{array}$ \\
\hline Termination & - & No field data available \\
\hline
\end{tabular}


Table 2 Borehole classification based on dip and azimuth

\begin{tabular}{lllll}
\hline $\begin{array}{l}\text { Borehole } \\
\text { group ID }\end{array}$ & $\begin{array}{l}\text { Dip angle } \\
\text { (degrees) }\end{array}$ & $\begin{array}{l}\text { Dip direction } \\
\text { (degrees) }\end{array}$ & $\begin{array}{l}\text { Calculated } \\
\text { conversion factor }\end{array}$ & $\begin{array}{l}\text { Number of } \\
\text { boreholes }\end{array}$ \\
\hline 1 & 4 & 91.1 & 1.679 & 1 \\
2 & 20 & 180.1 & 1.458 & 1 \\
3 & 41 & 71 & 1.691 & 1 \\
4 & $44-56$ & $314-326$ & 1.776 & 3 \\
5 & $35-54$ & $2-359$ & 1.642 & 3 \\
6 & $51-72$ & $287-308$ & 1.919 & 9 \\
7 & $69-80$ & $38-40$ & 1.694 & 2 \\
8 & $54-76$ & $271-277$ & 1.727 & 4 \\
9 & $71-89$ & $0-354$ & 1.691 & 7 \\
10 & 78 & 340 & 1.730 & 1 \\
11 & $78-87$ & $222-244$ & 1.730 & 4 \\
12 & $73-86$ & $304-318$ & 1.751 & 5 \\
13 & 83 & 160 & 1.635 & 1 \\
14 & $83-89$ & $86-92$ & 1.653 & 2 \\
\hline
\end{tabular}

Step 3: Step 2 was repeated 30 times to account for the stochastic nature of DFN model. Then, a linear relationship between input $\left(P_{32}\right)$ and output $\left(P_{10}\right)$ was established for each group of boreholes (Figure 5).

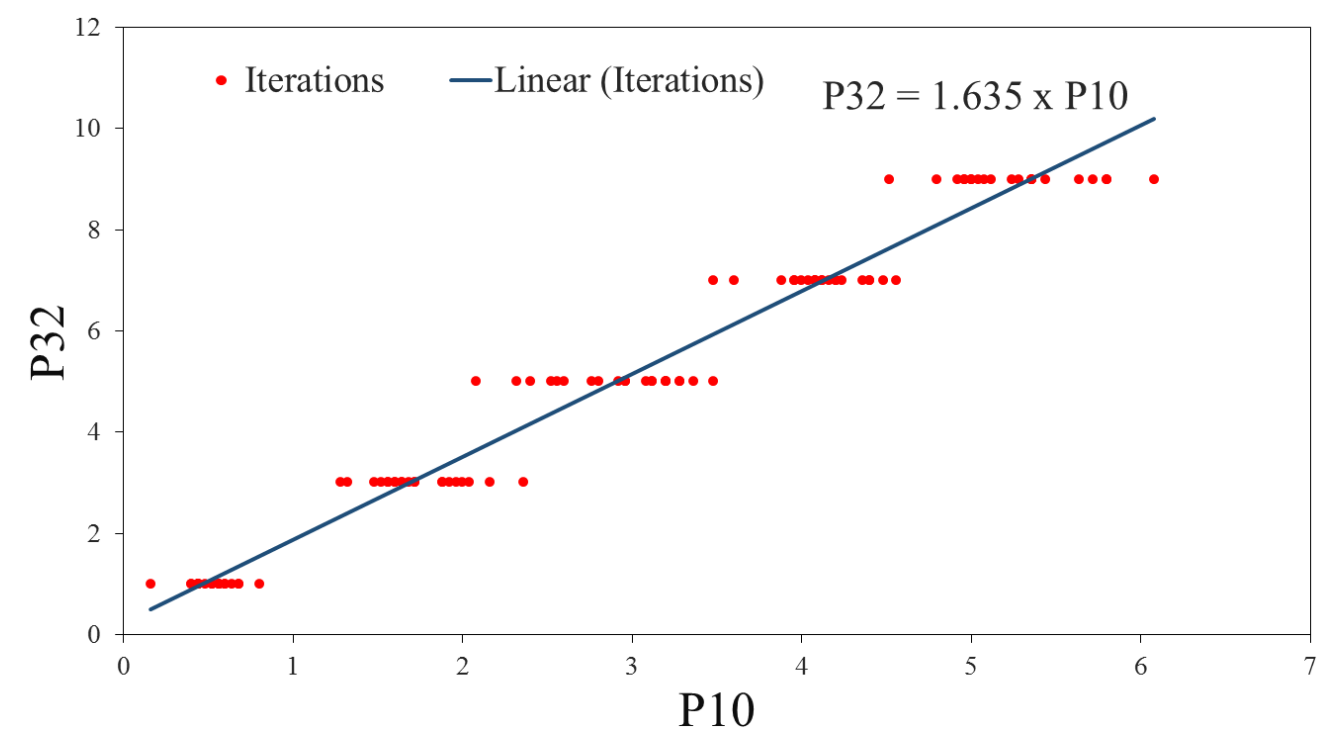

Figure 5 Example of determination of conversion factor by simulation (Munkhchuluun 2017) 
Using the relationship, $\mathrm{P}_{10}$ values logged in boreholes can be transferred into $\mathrm{P}_{32}$ values using their respective conversion factors. The resultant $P_{32}$ values were distributed throughout the block model using ordinary kriging, then conventional geostatistics (Figure 6). The major structures were deterministically located in the block model and assigned a $\mathrm{P}_{32}$ equal to 20 , which takes $8 \%$ of total volume. However, a fault zone with a thickness less than $10 \mathrm{~m}$ would be overestimated in the block model as the minimum cell size in the block model was $10 \times 10 \times 10 \mathrm{~m}$. Alternatives include, but are not limited to, using a variable cell size, and inserting the faults as deterministic surfaces and adding a 'distance-to-fault' correction to the $P_{32}$. Due to computational difficulty and availability of field data, this was not feasible.

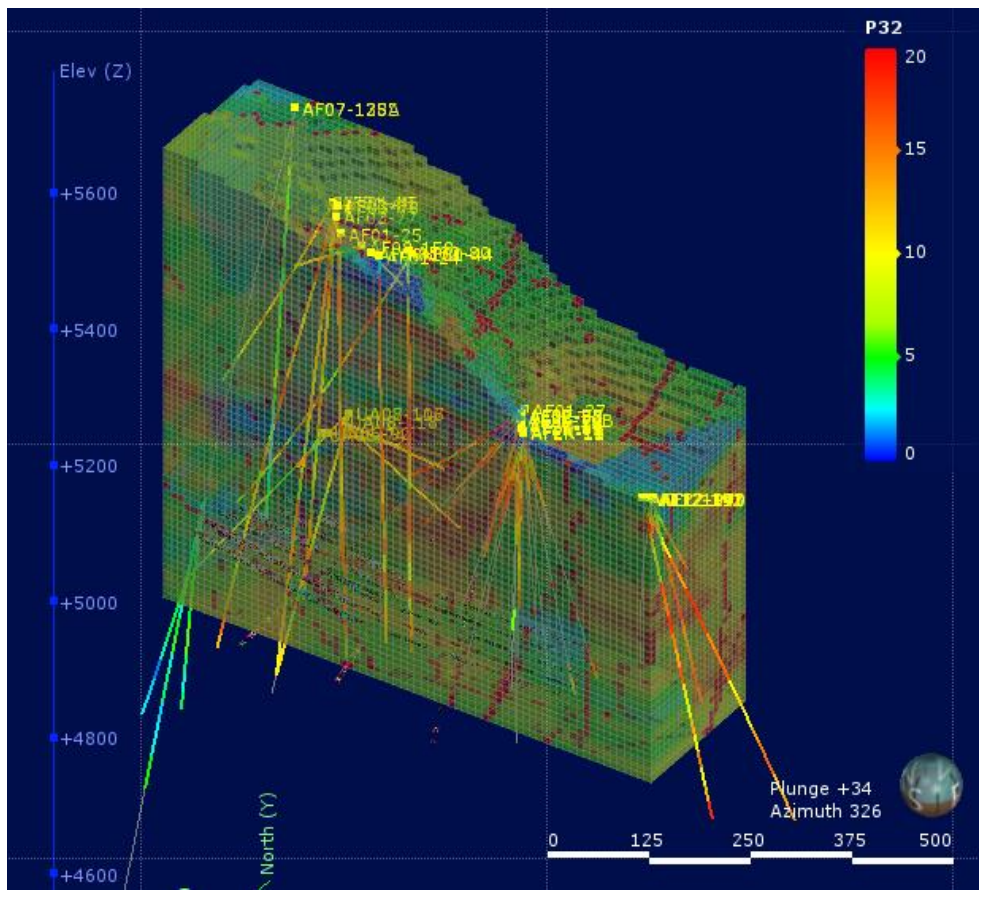

Figure 6 Geostatistical $P_{32}$ block model

\section{Comparison of $\mathrm{P}_{32}$ and drawpoint hang-up production data}

Recorded hang-up events (HUPs), a simple indicator of fragmentation, was the biggest dataset which was collected for the longest span of mine operating time. The accuracy of hang-up logs as an indicator of fragmentation size is limited due to the fact that some drawpoints may be hung up above the drawpoint and allow material to flow through for production. In this case, such a drawpoint may still be classified as being 'active'. From the results of image-based secondary fragmentation measurements (Munkhchuluun 2017), it was observed that some drawpoint size distributions significantly deviated from that of adjacent drawpoint measurements. This may have been due to the fines sieving effect.

The number of HUPs recorded during each month was divided by the corresponding monthly tonnage to determine the HUP frequency for each month in proportion to the quantity of material handled. Using Dassault Systèmes PCBC ${ }^{T M}$ (Dassault Systèmes 2018) industry standard cave scheduling software, HUP frequency can be related back to total tonnage pulled from the drawpoint and the height of draw (HOD), which is measured from the extraction level.

The DFN-based $P_{32}$ block model was used as an input into PCBC. New Afton Mine's PCBC parameters (such as shape and size of the draw column, and drawbell), and historic production schedules were used to provide monthly reports of $\mathrm{P}_{32}$ values and the corresponding HOD for each drawpoint. New Afton's current template mixing model was utilised as a mixing model. Since conventional ellipsoid flow theory (REBOP, PCBC and cellular automata) is being questioned by recent flow marker experiments (Brunton et al. 2016), the HOD estimated from PCBC should be considered as an approximation. 
The influence of in situ fragmentation and HOD on HUP is illustrated by the results from individual drawpoints. Two drawpoints (C05S and D13S) are chosen to illustrate drawpoint-based analysis (Figure 7). Drawpoint C05S was located at the edge of the B2 Cave where the caving has initiated, while drawpoint D13S was located in the middle of the B2 Cave. C05S has coarser blocks than D13S. Both draw columns showed nonlinear trends of $P_{32}$ with HOD. Also, higher values of $P_{32}$ coincides with HUPs. Drawpoint C05S experienced more frequent HUPs than the finer D13S drawpoint. Furthermore, no HUPs were recorded for the selected drawpoints between intervals of HOD 120 and $150 \mathrm{~m}$, where $P_{32}$ values are the lowest. According to experience in DOZ Block Cave Mine, the HOD 50-150 m is likely to see the effect of secondary fragmentation (Moss, pers. comm., 4 August 2017). However, random HUPs are still observed even after the draw column matures (Bergen et al. 2015).

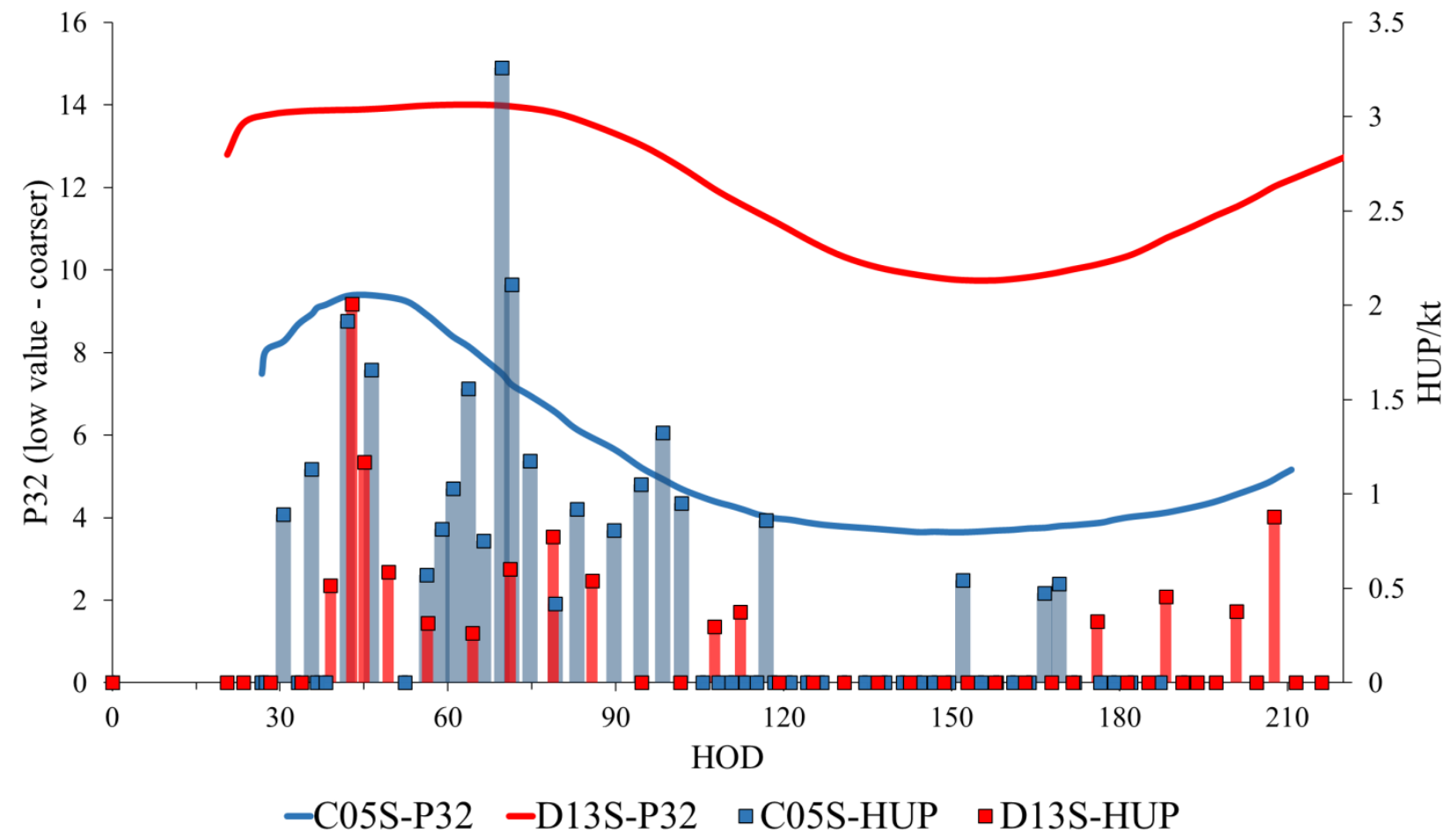

Figure 7 Comparison between HUPs and $\mathrm{P}_{32}$ for drawpoint C05S and D13S

Since a sampling error and a local anomaly could heavily influence the drawpoint-based analysis, a general conclusion cannot be reached from the analysis. The drawpoint-based analysis can be effective after clustering drawpoints based on their location, lithology and stress environment.

Datasets in the B1 Cave were small and were not considered adequate for analytical consideration. Therefore, cave-scale analysis was carried out in the B2 Cave according to following steps:

1. Across the B2 Cave, $P_{32}$ values and corresponding HUP frequency were pooled in every $10 \mathrm{~m}$ HOD.

2. Based on $P_{32}$ values, each pool was subdivided into 10 bins. In order to ensure that every bin is representative, each bin's $P_{32}$ threshold value was calculated to have an even number of data for each bin using Microsoft Excel's solver tool.

3. A scatter plot of average $P_{32}$ versus HUP/kt was generated, and trendlines are drawn from the data points (Figure 8). 


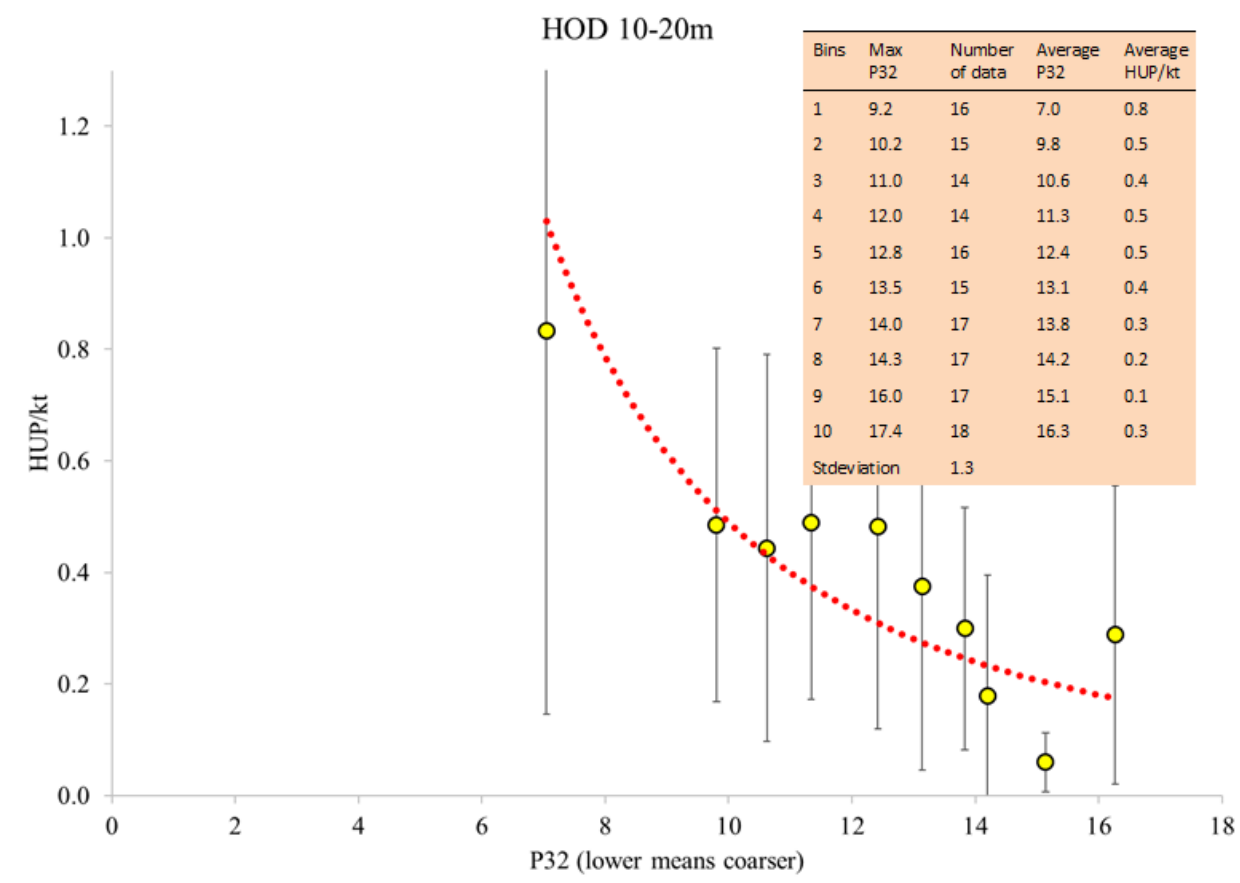

Figure 8 Example of distributing data points and drawing trendline (B2 Cave HOD 10-20 m)

Steps 1-3 were repeated for each slice of HOD. The results are put together in Figure 9 which indicate the following observations:

- The presence of in situ rock mass fractures correlates well with observed HUP frequency in low HOD $(20-100 \mathrm{~m})$. The correlation decreases as the HOD increases.

- As the $P_{32}$ becomes lower (which implies coarser fragmentation), the HUP frequency increases.

- For high HOD (above $100 \mathrm{~m}$ ), the $P_{32}$ values are barely relating to HUP frequency considering the horizontal linear trendlines.

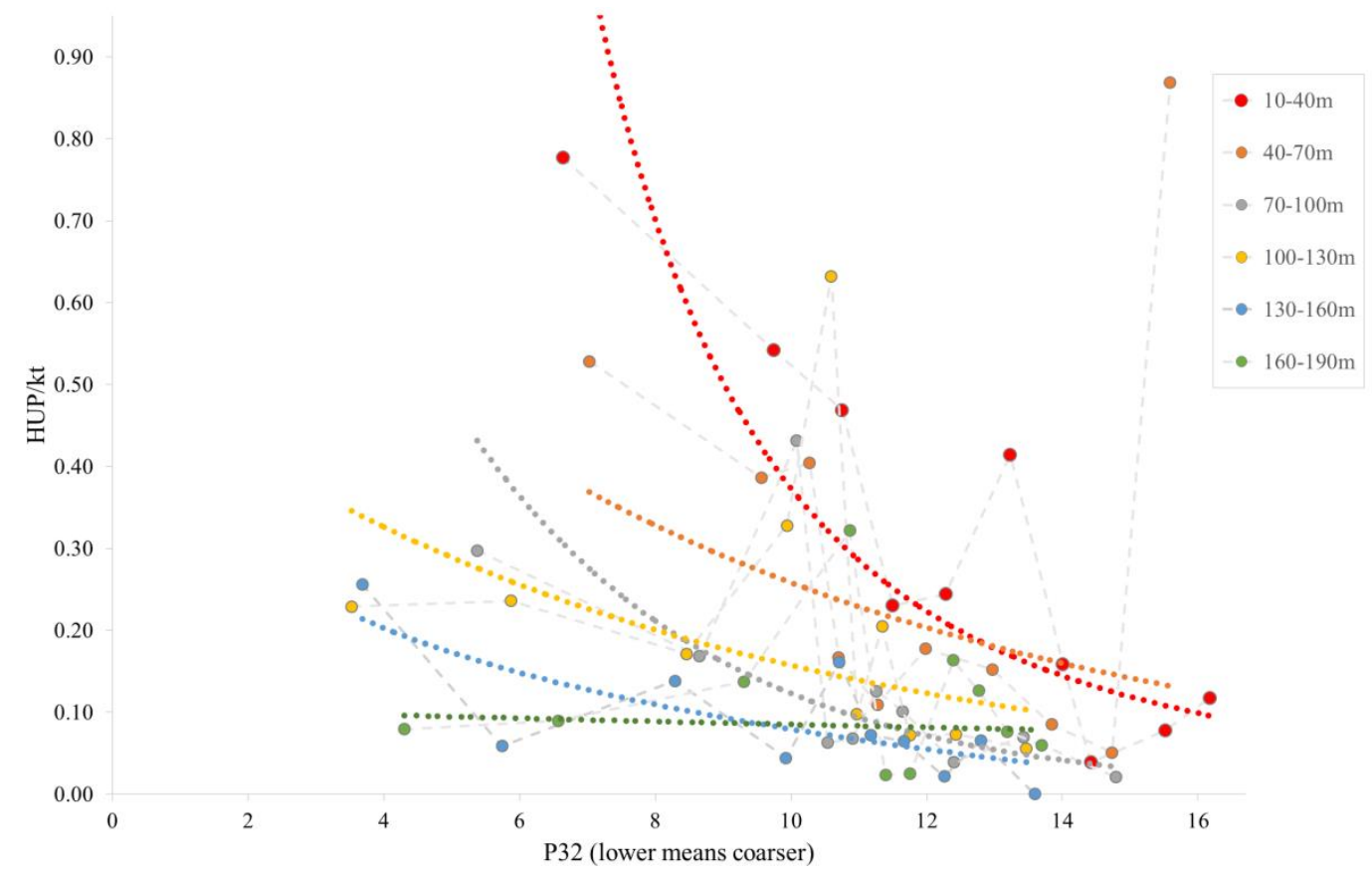

Figure 9 Cave-scale analysis (30 m interval slices - B1 Cave) 
The rock mass between the extraction level and HOD $40 \mathrm{~m}$ is typically heavily affected by ring blasting. There might be a practical use of DFN in implementing different blasting strategies for different zones of rock mass since their $P_{32}$ values agree fairly well with HUP frequency in the area.

From the blasted ground upward, primary and secondary fragmentation mechanisms control fragmentation with primary fragmentation playing the dominant role at lower HODs $(40-70 \mathrm{~m})$ due to relatively low residency times in the column seeing the close correlation between natural rock mass coarseness (low $\mathrm{P}_{32}$ ) and high HUP frequency.

From about HOD $100 \mathrm{~m}$, trendlines became almost flat indicating secondary fragmentation was the driving force for the fragmentation reporting to the drawpoint and in situ rock mass characteristics play a lesser role.

\section{Conclusion and recommendation}

In order to build a DFN model, it is important to adopt objective methodologies in data processing. In this research, piecewise linear interpolation was used for identifying fracture frequency domain, and $\mathrm{P}_{10}$ conditioning was carried out to overcome directional bias.

More frequent HUPs were reported from areas with low $\mathrm{P}_{32}$ values. The $\mathrm{P}_{32}$ value did not follow a linear straightforward trend below surface, but was controlled by structural domain.

Results showed that fragmentation of blasted ground and low HOD draw column at New Afton Mine are mainly dictated by presence of discontinuity, while the fragmentation of a matured HOD draw column can be primary controlled by secondary fragmentation.

It is worth noting that a generalisation was made for the fracture orientation as a bootstrapping method was employed. Significance of the methodology will be predominantly driven by abundance and quality of the data. The authors believe the method could work for other cave operations, as long as care is taken to collect the required data for the model. To date, data collection processes are not always amenable to statistical analysis, and geotechnical data may be available in large numbers at the beginning of a project.

\section{Acknowledgement}

The authors thank personnel at New Afton and New Gold for supporting the cave-to-mill project and providing access to samples and data from the New Afton block cave operation. The authors also thank the Natural Sciences and Engineering Research Council of Canada (NSERC) for the financial support provided to this research through a Collaborative Research Development grant (Grant No. 11R74149; Mine-to-Mill Integration for Block Cave Mines).

\section{References}

Bewick, RP, \& Kaiser, PK 2016, 'Characterisation and classification of veined rocks for rock mass behaviour assessment', Proceedings of MassMin 2016, The Australasian Institute of Mining and Metallurgy, Melbourne, pp. 825-834.

Bergen, RD, Krutzelmann, H \& Rennie, DW 2015, NI43-101: Technical Report on the New Afton Mine, British Columbia, Canada, Roscoe Postle and Associates Inc, Toronto.

Brown, ET 2003, Block Caving Geomechanics, Julius Kruttschnitt Mineral Research Centre, Indooroopilly, pp. 304-309.

Brunton, I, Lett, J, Sharrock, GB, Thornhill, T \& Mobilio, B 2016, 'Full-scale flow marker experiment at the Ridgeway Deeps and Cadia East block cave operations', Proceedings of MassMin 2016, The Australasian Institute of Mining and Metallurgy, Melbourne, pp. 141-150.

Dassault Systèmes 2018, PCBC, computer software, Dassault Systèmes, Paris, https://www.3ds.com/products-services/geovia/ products/pcbc/

Davies, AGL 2015, 'Case study: understanding the mechanics behind the rockmass deformation observed in an extraction strike drive at New Gold's New Afton Mine block cave operation', Proceedings of the 49th US Rock Mechanics/Geomechanics Symposium, American Rock Mechanics Association, Alexandria.

Dershowitz, WS \& Herda, HH 1992, 'Interpretation of fracture spacing and intensity', Proceedings of the 33rd US Rock Mechanics Symposium, American Rock Mechanics Association, Alexandria. 
Elmo, D, Stead, D \& Rogers, S 2015, 'Guidelines for the quantitative description of discontinuities for use in discrete fracture network engineering', Proceedings of the 13th ISRM Congress, International Society for Rock Mechanics and Rock Engineering, Lisbon, paper 587.

Elmo, D, Liu, Y \& Rogers, S 2014a, 'Principles of discrete fracture network modelling for geotechnical applications', Proceedings of the 1st International Conference on Discrete Fracture Networking, Canadian Rock Mechanics Association.

Elmo, D 2014b, MINE485: Cave Mining System, week 6 notes - fragmentation, class handout, Norman B. Keevil Institute of Mining Engineering, University of British Columbia, Vancouver.

Elmo, D, Rogers, S, Stead, D \& Eberhardt, E 2014c, 'A discrete fracture network approach to characterize rock mass fragmentation and implication for geomechanical upscaling', Transaction of the Institutions of Mining and Metallurgy, vol. 123, no. 3, pp. 149-161, https://dx.doi.org/10.1179/1743286314Y.0000000064

Elmo, D, Stead, D \& Rogers, S 2008, 'Quantitative analysis of fractured rock masses using a discrete fracture network approach: characterisation of natural fragmentation and implication for current rock mass classification system', in $\mathrm{H}$ Schunnesson \& E Nordlnd (eds), Proceedings of MassMin 2008, Luleå University of Technology, Luleå, pp. 1023-1032.

Jakubec, J 2013, 'Role of defects in rock mass classification', in Y Potvin \& B Brady (eds), Proceedings of the Seventh International Symposium on Ground Support in Mining and Underground Construction, Australian Centre for Geomechanics, Perth, pp. 337-344.

Kaiser, PK, Amann, F \& Bewick, RP 2015, 'Overcoming challenges of rock mass characterization for underground construction in deep mines', Proceedings of the 13th International Congress of Rock Mechanics, International Society for Rock Mechanics and Rock Engineering, Lisbon.

Munkhchuluun, M 2017, Linking the Fracture Intensity of an In Situ Rock Mass to Block Cave Mine Fragmentation, MAsc thesis, The University of British Columbia, Vancouver, https://open.library.ubc.ca/clRcle/collections/24/items/1.0354566

Munkhchuluun, M, Elmo, D, Nadolski, S \& Klein, B 2018, 'A piecewise linear interpolation algorithm to reduce the uncertainty of cumulative fracture intensity plots for discrete fracture network modelling', Proceedings of the 15th International Conference of the International Association for Computer Methods and Advances in Geomechanics, Institute of Rock and Soil Mechanics, Chinese Academy of Sciences, Wuhan.

Nadolski, S, Munkhchuluun, M, Klein, B, Elmo, D \& Hart, C 2017, 'Cave fragmentation in a cave-to-mill context at the New Afton Mine part I: fragmentation and hang-up frequency prediction', Mining Technology: Transactions of the Institutions of Mining and Metallurgy, vol. 127, no. 2, pp. 75-83, https://dx.doi.org/10.1080/14749009.2017.1351115

Turichshev, A \& Hadjigeorgiou, J 2015, 'Experimental and numerical investigation into the strength of intact veined rock', Rock Mechanics and Rock Engineering, vol. 48, no. 5, pp. 1897-1912.

Vyazmensky, A, Elmo, D \& Stead, D 2010, 'Role of rock mass fabric and faulting in the development of block caving induced surface subsidence', Rock Mechanics and Rock Engineering, vol. 43, no. 5, pp. 533-556, https://dx.doi.org/10.1007/s00603-0090069-6 